\title{
The Preparation of Preserved Shallot Powders and a Pilot Study of the Antioxidative Effect of Their Aqueous Extracts on the Formation of Hydroxyl Radical Species
}

\author{
Ji-Yuan Liang, An-Chi Hsu*, Xin-Yu Lan", Kuan-Yu Chen, Po-Shuan Chen, Wei-Ming Chou, \\ Kuei-Yan Liou, Dung-Yu Peng, Jeu-Ming P. Yuann \\ Department of Biotechnology, Ming Chuan University, Taoyuan County, Taiwan \\ Email: \#yuann@mail.mcu.edu.tw
}

Received August 30, 2012; revised September 29, 2012; accepted October 10, 2012

\begin{abstract}
In order to preserve the nutrients in shallots, after harvest, various protocols, including incubation, drying or lyophilization of the shallot are developed in this study. Using aqueous extracts of ground shallot powders, this study examines the antioxidative properties of shallots on the formation of hydroxyl radical species ( $\left.{ }^{\circ} \mathrm{OH}\right)$ generated via a Fenton-type reaction. A ribose degradation assay shows that all aqueous extracts of shallot prepared in this study exhibit enhanced levels of ${ }^{\circ} \mathrm{OH}$, suggesting that processed shallot, like strong reductants such as ascorbate, has a strong reducing power, which converts $\mathrm{Fe}^{3+}$ to $\mathrm{Fe}^{2+}$ in a Fenton's reaction and increases the levels of ${ }^{\circ} \mathrm{OH}$. A DNA integrity assay shows that fragmentation of super-coiled plasmid DNA, pGEM-7Zf(-), by ${ }^{\circ} \mathrm{OH}$ is diminished in the presence of all shallot aqueous extracts, albeit to various extents. Finally, electron paramagnetic resonance (EPR) experiments show that lyophilized shallot completely scavenges ${ }^{\circ} \mathrm{OH}$, as evidenced by the disappearance of the EPR-active reaction product generated between spin trap, 5,5-dimethyl-1-pyrroline-N-oxide (DMPO), and ${ }^{\circ} \mathrm{OH}$. The results of this study show the potential of a daily intake of preserved shallot to boost antioxidative protection against the toxicity of ${ }^{\circ} \mathrm{OH}$ or any other damaging radicals.
\end{abstract}

Keywords: 2'-Deoxy-D-Ribose; EPR; Fenton's Reaction; Hydroxyl Radical; Plasmid DNA; Shallot

\section{Introduction}

Extracts of plant foods have been shown to exhibit an antioxidant effect and a capacity to scavenge free radicals, to protect against external and endogenous agents in the treatment of human health problems [1-4]. Of these extracts, shallot (Allium ascalonicum L.) has been used as a food additive in Chinese society for generations. Shallot is mainly grown in southern Taiwan, but it can be harvested only once a year. Therefore, the preservation of shallot is an important issue for both farmers and people who use shallot as a dietary additive, because of its unique fragrance. In Taiwan, shallot is mostly preserved by frying, which maintains its fragrance, but this may not be a good method of preserving its nutrients, since the consumption of deep-fried food has been identified as one of the risk factors of lung cancer, in Sichuan, China [5].

This study develops three different protocols for removing the water in shallot purchased from a local food store. Firstly, the shallot is incubated to increase its fla-

\footnotetext{
*These three authors contributed equally to this work.

${ }^{\#}$ Corresponding author.
}

vor, presumably through a Maillard reaction, followed by heating. Secondly, the shallot is directly dried by heating, in order to ascertain whether incubation has any effect on the antioxidative activity of the incubated shallot. Thirdly, the shallot is firstly frozen, followed by lyophilization, in order to develop a protocol by which shallot can be preserved at lower temperature. The dried shallot prepared according to these methods is then ground into a powder, for long-term storage.

Analysis of the shallot extracts has confirmed the presence of flavone and polyphenolic compounds, such as quercetin and its derivatives, which suggest that shallot may exhibit antioxidant properties [6-8]. In order to examine the antioxidative properties of shallot prepared according to these proposed protocols, aqueous extracts of the three types of shallot powder were subjected to reactions, in order to investigate their ability to scavenge 'OH generated via a Fenton-type reaction $\left(\mathrm{Fe}^{2+}+\mathrm{H}_{2} \mathrm{O}_{2}\right.$ $\left.\rightarrow \mathrm{Fe}^{3+}+{ }^{-} \mathrm{OH}+{ }^{\circ} \mathrm{OH}\right)$. Hydroxyl radical, an oxygen-derived radical species, has been implicated in the carcinogenesis of many types of cancer, such as gastric cancer, by causing tissue damage and thus allowing the 
cancer to spread [9]. The acceleration of gastric carcinogenesis by sodium chloride may be mediated by ${ }^{\circ} \mathrm{OH}[10]$. Moreover, in a meta-analysis, consumption of large amounts of allium vegetables (onions, garlic, shallot) has recently been shown to reduce the risk of gastric cancer [11], but there is no credible evidence to support a relationship between garlic intake and a reduced risk of gastric, breast, lung or endometrial cancer [12]. Extracts of shallot have previously been shown to scavenge positively charged radical species, 2,2'-azinobis(3-ethylbenzothiazoline-6-sulfonic acid), $\mathrm{ABTS}^{\cdot+}$, more efficiently than those of garlic, although shallot and garlic similarly inhibit the protein hydroperoxides caused by ${ }^{\circ} \mathrm{OH}$ [13]. The hydroxyl radical is more easily diffused and more toxic than $\mathrm{ABTS}^{\circ+}$ [14], but a comparison of the direct 'OH-scavenging ability of shallot and garlic aqueous extracts has not been documented. In this study, the ${ }^{\circ} \mathrm{OH}-$ scavenging effects of shallot were evaluated by their influence on ribose degradation, super-coiled plasmid DNA integration and EPR spin-trapping. The results show that aqueous extracts of shallot powders behave as a reductant in a ribose degradation assay, while in the DNA integrity assay and EPR experiments, they act as a ${ }^{\circ} \mathrm{OH}$ scavenger. Because of the widespread use of shallot and other types of allium vegetables by many populations, this study provides important nutritional guidelines for the use of shallot as a food additive.

\section{Materials and Methods}

All chemicals were reagent grade or better and used without further purification. The de-ionized water (D.I. $\mathrm{H}_{2} \mathrm{O}$ ) used to make solutions was redistilled using a Waters water distillation system. The fresh shallot and garlic used for the EPR experiments were purchased from a local food store in Taoyuan County, Taiwan, and preserved immediately upon arrival, by freezing at $-20^{\circ} \mathrm{C}$, until preparation commenced. Ferrous ammonium sulfate 6-hydrate $\left[\mathrm{Fe}\left(\mathrm{NH}_{4}\right)_{2}\left(\mathrm{SO}_{4}\right)_{2} \cdot 6 \mathrm{H}_{2} \mathrm{O}\right]$ was purchased from J.T. Baker (Phillipsburg, NJ). Ascorbic acid, 2'-deoxyD-ribose, DMPO, 2'-thiobarbituric acid (TBA) and tris (hydroxymethyl)aminomethane (Trizma base or Tris) were purchased from Sigma-Aldrich (St. Louis, MO). Hydrogen peroxide $\left(\mathrm{H}_{2} \mathrm{O}_{2}\right)$ was purchased from T.K. Chemical Co. (Tainan, Taiwan). The reagent used to stain DNA was HealthView Nucleic Acid Stain, purchased from Genomics Co. (Shiji, Taiwan).

All solutions were prepared using D.I. water or the solvents noted; otherwise. Stock solutions of ferrous ammonium sulfate $(6 \mathrm{mM})$ and 2'-deoxy-D-ribose (1 $\mathrm{m} M$ in $60 \mathrm{~m} M$ Tris at $\mathrm{pH} \mathrm{7.0)}$ were prepared, loaded in $1.5 \mathrm{ml}$ Eppendorf tubes and frozen at $-20^{\circ} \mathrm{C}$, until experimentation. Because of their instability, shallot aqueous extracts, $\mathrm{H}_{2} \mathrm{O}_{2}(60 \mathrm{~m} M)$ and TBA $(1 \%$ in $50 \mathrm{~m} M \mathrm{NaOH})$ were all freshly prepared, prior to each experiment.

\subsection{Preparation of Preserved Shallot}

This study develops three different protocols to preserve shallot, as described briefly below. Firstly, the shallot was incubated in an incubator, at a constant $85^{\circ} \mathrm{C}$ and $85 \%$ humidity, for 12 days, followed by three-days of heat drying in an oven at $60^{\circ} \mathrm{C}$. The heat-dried shallot, shallot was directly dried in an oven at $60^{\circ} \mathrm{C}$ for three days. The lyophilized shallot was frozen and lyophilized, to remove all water content. After preparation, all three types of shallot were ground to a powder, for anaerobic storage. The shallot powders were freshly dissolved in D.I. water, to produce a $10 \%(\mathrm{w} / \mathrm{v})$ aqueous extract, followed by centrifugation at $10,000 \mathrm{~g}$, to remove debris that was not dissolved, and the supernatant was saved for analysis.

\subsection{Assay of 2'-deoxy-D-ribose Degradation}

The generation of ${ }^{\circ} \mathrm{OH}$ via a Fenton-type reaction was quantified using 2'-deoxy-D-ribose oxidative degradation, as described previously, with minor modifications [15]. The assay quantifies the 2'-deoxy-D-ribose degradation product, malondialdehyde (MDA), by its condensation with TBA under acidic conditions. In a typical experiment, $30 \mu \mathrm{l}$ 2'-deoxy-D-ribose (1 $\mathrm{m} M$ in $60 \mathrm{~m} M$ Tris at $\mathrm{pH}$ 7.0) was first added to the bottom of a 1.5-ml Eppendorf tube. Then, solutions of $\mathrm{H}_{2} \mathrm{O}_{2}(60 \mathrm{mM})$ and D.I. water (control), or an aqueous solution of shallot extract in a volume of $10 \mu \mathrm{l}$ each were added as two individual drops to the wall of the tube. Each reaction was initiated by firstly mixing the two solution drops on the wall with a pipette tip containing $10 \mu \mathrm{Fe}^{2+}(6 \mathrm{mM}$ in $60 \mathrm{~m} M$ Tris at $\mathrm{pH}$ 7.0) and then introducing the mixed solution to the 2'-deoxy-D-ribose solution, followed by the addition of $\mathrm{Fe}^{2+}$ to the reaction solution. Therefore, the final volume of each reaction solution was $60 \mu \mathrm{l}$ and the concentrations of 2'-deoxy-D-ribose, $\mathrm{H}_{2} \mathrm{O}_{2}$, and $\mathrm{Fe}^{2+}$ were $0.5,10$, and $1 \mathrm{mM}$, respectively. After $80 \mathrm{~s}$ (1.33 $\mathrm{min})$, the reactions were terminated by adding $4 \%$ phosphoric acid (v/v) of $60 \mu \mathrm{l}$, followed by $60 \mu \mathrm{l}$ of 1\% TBA. After boiling for $15 \mathrm{~min}, 60 \mathrm{~m} M$ Tris at $\mathrm{pH} 7.0$ of $720 \mu \mathrm{l}$ was then added to each solution, to produce a final volume of $900 \mu$, prior to spectrophotometric measurement at $532 \mathrm{~nm}$. The measurement of the absorbance of each reaction solution was performed at room temperature in a Perkin-Elmer spectrophotometer of type Lambda35, equipped with a quartz cuvette of $1 \mathrm{~cm}$ light path. In order to remove the absorbance from the shallot aqueous solution in each experiment, the absorbance from a solution processed under the same conditions, in the absence of a Fenton's reaction, was measured and subtracted from the total absorbance. 


\subsection{DNA Integrity Assay}

The DNA integrity assay was performed using supercoiled plasmid DNA as the target molecule. Plasmid DNA, pGEM-7Zf(-), was transformed into E. coli, $\mathrm{DH} 5 \alpha$, and grown overnight in $\mathrm{LB}$ broth at $37^{\circ} \mathrm{C}$. The culture was then harvested and the DNA was purified using a Plasmid Miniprep kit (BioKit, Miaoli, Taiwan). After purification, $6 \mu \mathrm{l}$ plasmid DNA dissolved in D.I. water was added drop-wise onto a piece of parafilm prior to the addition of other reagents. Then, $2 \mu$ D.I. water or shallot aqueous extract and $2 \mu \mathrm{l} 60 \mathrm{~m} M \mathrm{H}_{2} \mathrm{O}_{2}$ were added onto the parafilm close to the plasmid DNA solution as two drops. Finally, a pipette tip holding $6 \mathrm{mM} \mathrm{Fe} \mathrm{F}^{2+}$ of 2 $\mu \mathrm{l}$ in $60 \mathrm{~m} M$ Tris at $\mathrm{pH} 7.0$ was used to mix the water or shallot aqueous extract and $\mathrm{H}_{2} \mathrm{O}_{2}$ together and to transfer this mixed solution into the DNA solution, followed by the addition of $\mathrm{Fe}^{2+}$, to initiate the reaction. After $80 \mathrm{~s}$, the reaction was quenched by adding $2 \mu$ l loading dye $(0.25 \%$ bromophenol blue and $40 \%$ sucrose), prior to electrophoresis in a $1.5 \%$ agarose gel. The plasmid DNA was visualized by internally staining the gel with Health View Nucleic Acid Stain.

\subsection{EPR Experiments}

Previous results showed that DMPO can be oxidized to generate the EPR-active species, DMPO-OH, under acidic conditions ( $\mathrm{pH} 3.0$ - 6.0), without involving ${ }^{\circ} \mathrm{OH}$ (data not shown). The EPR experiments in this study were therefore performed under slightly alkaline conditions ( $\mathrm{pH}$ 8.0) to avoid this situation. Stock DMPO solution of $200 \mathrm{~m} M$ was produced by dissolving DMPO in Tris- $\mathrm{HCl}(100 \mathrm{~m} M$ at $\mathrm{pH} 8.0)$, followed by washing with charcoal, to remove impurities, and filtering through an acrodisc of $0.45 \mu \mathrm{m}$. In a typical EPR experiment, $45 \mu \mathrm{l}$ DMPO solution was first added onto a piece of parafilm. Fifteen- $\mu$ l D.I. water or $10 \%$ shallot aqueous extract and $15 \mu \mathrm{H}_{2} \mathrm{O}_{2}$ were added as two drops, close to the DMPO solution. Then, a pipette tip holding $15 \mu \mathrm{Fe}^{2+}$ in 100 $\mathrm{m} M$ Tris- $\mathrm{HCl}$ at $\mathrm{pH} 8.0$ was used to mix water or shallot aqueous extracts and $\mathrm{H}_{2} \mathrm{O}_{2}$ together and to transfer the mixed solution to the DMPO solution, followed by the injection of $\mathrm{Fe}^{2+}$ solution. Then, the entire reaction solution was drawn into a capillary tube, sealed with Vaseline grease and loaded into an EPR quartz tube for measurement. The reaction was allowed to continue for $8 \mathrm{~min}$, prior to EPR data collection. A Bruker EMX-10 X-band EPR spectrometer was used for the measurement of DMPO-OH at room temperature. The parameters for obtaining the EPR spectra were as follows. Instrumental conditions were: microwave frequency, $9.765 \mathrm{GHz}$; microwave power, $19.97 \mathrm{~mW}$; modulation amplitude, 1G; scan time, $168 \mathrm{~s}$; time constant, $20.48 \mathrm{~ms}$ and scan range,
$100 \mathrm{G}$. The EPR measurements for DMPO alone were performed before and after the experiment, to ensure that the EPR-active species produced by the oxidation of DMPO was not interfering with the experiments. The results show that no EPR signals from these species were detected.

\subsection{Statistical Analysis}

In the ribose degradation experiments, the results are expressed as mean \pm standard deviation (SD). A one-way analysis of variance (ANOVA) was performed to compare means of two or more samples. When statistically significant differences were found, an unpaired Student's $t$-test was used. A value of $p<0.05$ is considered to be statistically significant.

\section{Results}

\subsection{Preparations of Preserved Shallot}

This study develops three different protocols to preserve shallot in powder form, as described above. It appears that heat-dried shallot, with or without incubation, becomes dark, while lyophilized shallot remains pink, with little change in its color. Additionally, all three types of shallot were ground into powder, for long-term storage, without much difficulty. The antioxidative experiments conducted in this study show that the dried powder form appears to be effective in preserving the nutrient content of shallot or other allium vegetables.

\subsection{2'-Dexoy-D-Ribose Degradation Assay}

In order to examine the effect of shallot aqueous extract on ribose degradation due to hydrogen abstraction caused by 'OH, 2'-dexoy-D-ribose was subjected to a Fenton-type reaction, to generate reactive ${ }^{\circ} \mathrm{OH}$, and one of the rearranged products, malondialdehyde (MDA) from ribose degradation, and its complex with TBA, MDATBA, were measured in acidic conditions at $532 \mathrm{~nm}$. As shown in Figure 1, the level of the MDA-TBA complex is relatively low in the absence of any shallot aqueous extracts, whereas the levels of the complex are greatly increased in the presence of aqueous extracts of all three types of shallot prepared in this study. In other words, in the ribose degradation assay, the aqueous extracts of shallot prepared under current conditions do not exhibit any ${ }^{\circ} \mathrm{OH}$-scavenging effects against ${ }^{\circ} \mathrm{OH}$, but instead increase the degradation of ribose, as shown in Figure 1. The increase in ribose degradation in the presence of all three types of shallot aqueous extract is most likely due to the reducing power of shallot, which converts $\mathrm{Fe}^{3+}$ to $\mathrm{Fe}^{2+}$, which then reacts with excess $\mathrm{H}_{2} \mathrm{O}_{2}(60 \mathrm{mM})$ to generate ${ }^{\circ} \mathrm{OH}$ continuously. Under the same conditions, 


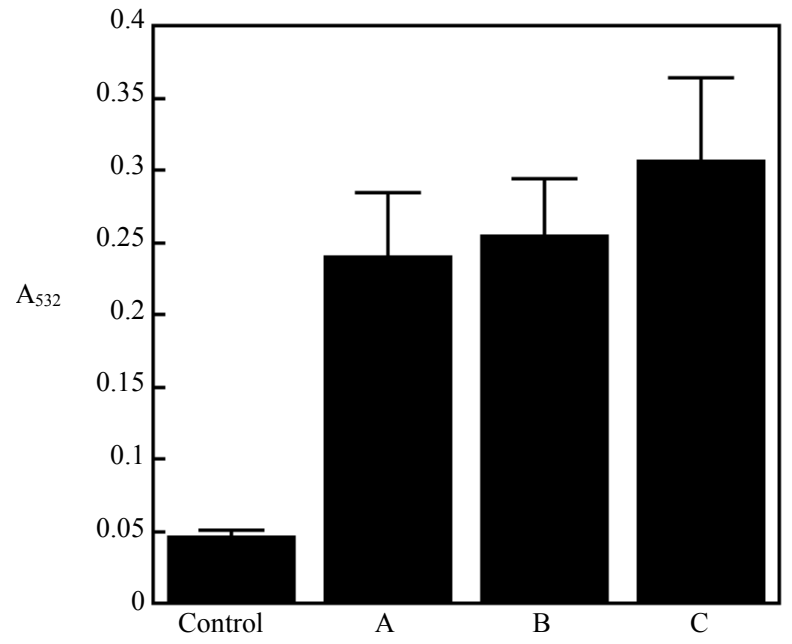

Figure 1. Ribose degradation by hydroxyl radical species generated via a Fenton's reaction, in the presence of aqueous extracts of (A) Incubated shallot; (B) Heat-dried shallot and (C) Lyophilized shallot. The control used D.I. water. Data are represented as mean \pm SD, where $n=3$.

ascorbate, a reductant known to enhance a Fenton-type reaction [16], causes a much greater increase in the levels of MDA-TBA (data not shown).

\subsection{DNA Integrity Assay}

DNA cleavage caused by ${ }^{\circ} \mathrm{OH}$ have been extensively studied [17]. In order to examine the levels of DNA strand breaks caused by ${ }^{\circ} \mathrm{OH}$ in the presence of shallot aqueous extracts, super-coiled plasmid DNA was allowed to react with ${ }^{\circ} \mathrm{OH}$ generated via a Fenton-type reaction, in the absence or presence of shallot aqueous extracts. In Figure 2, lane 1, super-coiled plasmid DNA alone is visualized. In lane 2, complete DNA digestion caused by ${ }^{\circ} \mathrm{OH}$ is seen, as shown by the disappearance of DNA bands in gel analysis. In lanes 3-5, in the presence of $10 \%$ aqueous extracts of shallot, plasmid DNA bands are all retained, although mostly in linear form, instead of super-coiled forms, with the heat-dried shallot aqueous extract retaining the largest amount of both super-coiled and linear DNA. These results suggest that the ingredients in the aqueous extracts of shallot scavenge ${ }^{\circ} \mathrm{OH}$ and decrease the levels of DNA cleavage.

\subsection{EPR Experiments}

The results from ribose degradation and DNA integrity assay seem contradictory, so the ${ }^{\circ} \mathrm{OH}$ scavenging effect of the aqueous extract of lyophilized shallot on the levels of ${ }^{\circ} \mathrm{OH}$ were further examined using EPR and spin trap, DMPO. Hydroxyl radical reacts with DMPO to generate EPR-active nitroxide, DMPO-OH, as evidenced by a quartet EPR splitting of 1:2:2:1 ratio [18]. Lyophilized shallot was selected for the EPR experiment, mainly be- cause of its ease of preparation compared to the other two types of shallot prepared in this study. For comparison purposes, lyophilized garlic aqueous extract was used as a control, since garlic (both the homogenate of $10 \%$ physiological saline solution and its supernatant) has been shown to decrease the level of ${ }^{\circ} \mathrm{OH}$ trapped by phenyl-butyl-nitrone for EPR measurements [19]. As shown in Figure 3(a), ${ }^{\circ} \mathrm{OH}$ generated in a Fenton-type reaction reacts with DMPO to generate the EPR-active species, DMPO-OH. In Figure 3(b), under the same conditions as in 3(a), except in the presence of lyophilized shallot aqueous extract, it is seen that the EPR signals of DMPO-OH completely disappear. In Figure 3(c), under the same conditions as 3(a), except in the presence of lyophilized garlic aqueous extract, the EPR signals of

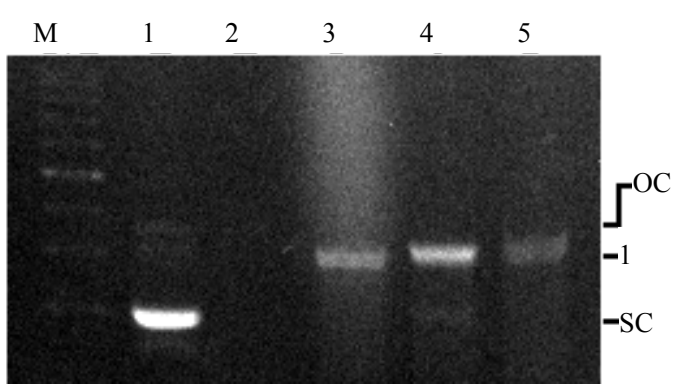

Figure 2. The DNA integrity assay of the aqueous extracts of shallot powders prepared in this study: Lane $M, 1 \mathrm{~kb}$ DNA marker; Lane 1, plasmid DNA, pGEM-7Zf(-), alone; Lane 2, plasmid DNA in a Fenton's reaction; Lanes 3-5, plasmid DNA in a Fenton's reaction in the presence of aqueous extracts of incubated, heat-dried and lyophilized shallot powders, respectively. The notations, -oc, -l and -sc, represent open-circular, linear and super-coiled plasmid DNA, respectively.

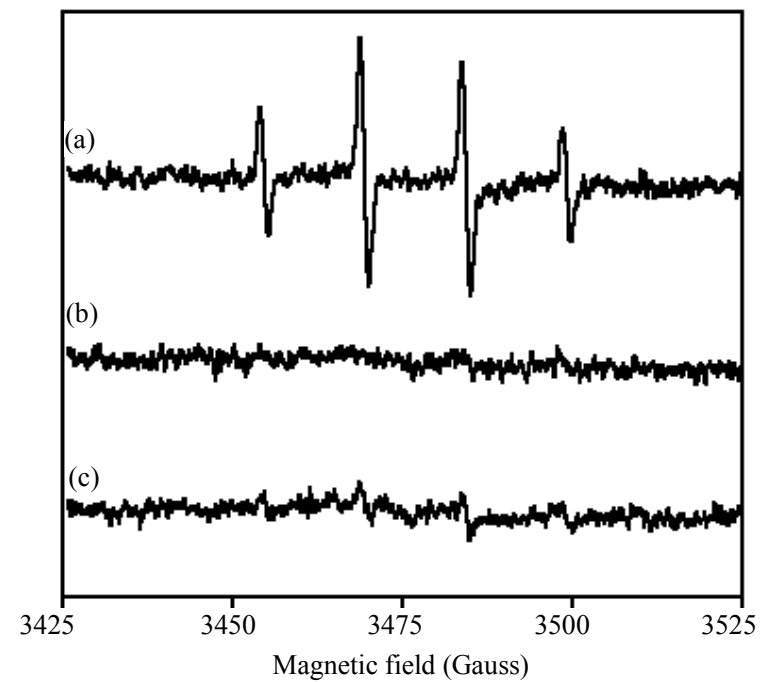

Figure 3. The EPR spectra of DMPO-OH generated in a Fenton's reaction in the presence of (a) D.I. water; (b) Aqueous extract of lyophilized shallot powder and (c) Aqueous extract of lyophilized garlic powder. 
DMPO-OH decrease to a much lower level than that of the control, but not to the extent that occurs in the presence of lyophilized shallot aqueous extract.

\section{Discussion}

The results of this study show that shallots harvested in Taiwan can be preserved in powder form for long-term storage without much difficulty, using three different protocols. The findings for the antioxidative effects of shallot aqueous extracts reveal that in the ribose degradation assay all three shallot aqueous extracts appear to increase the amount of the ${ }^{\circ} \mathrm{OH}$ radical, instead of scavenging, as expected. In the DNA integrity assay, shallot aqueous extracts are seen to scavenge ${ }^{\circ} \mathrm{OH}$ and to decrease the level of DNA cleavage. Lastly, in the EPR experiments, lyophilized shallot aqueous extract is seen to have a scavenging ability and completely eliminates ${ }^{\circ} \mathrm{OH}$, compared with garlic aqueous extract, a known ${ }^{\circ} \mathrm{OH}$ scavenger [19], which only partially eliminates ${ }^{\circ} \mathrm{OH}$.

Meta-analysis has shown that shallot reduces the risk of gastric cancer, but only if a large amount of shallot is consumed [11]. The solubility and bioavailability of exemestane, an irreversible aromatase inhibitor, has been found to greatly improve in powder and tablet form [20], so the beneficial effects of shallot powders prepared using these protocols are increased if the shallot powder is dissolved in water or other types of solvents. The longterm health benefits of shallot aqueous extracts due to their antioxidative effect on human diseases deserves further investigation.

In the ribose degradation assay, all aqueous extracts of shallot powders increase the amount of ${ }^{\circ} \mathrm{OH}$, similarly to ascorbate, by reducing $\mathrm{Fe}^{3+}$ to $\mathrm{Fe}^{2+}$ in a Fenton's reaction, to continuously increase the levels of ${ }^{\circ} \mathrm{OH}$. This can be toxic, since an ascorbate-driven Fenton's reaction may be an important mechanism for cell death in biological systems [16]. However, in the DNA integrity assay, all aqueous extracts of shallot powders demonstrate ${ }^{\circ} \mathrm{OH}-\mathrm{scav}^{-}$ enging by decreasing the levels of DNA cleavage caused by ${ }^{\circ} \mathrm{OH}$. The contradiction in the results from these two assays can be partially explained by the hydrogen accessibility of ribose rings on the 2'-deoxy-D-ribose in ribose degradation assay and that of the sugar rings of duplex DNA in the DNA integrity assay. In the ribose degradation assay, the hydrogen atoms on the five carbon atoms (C5' $\sim \mathrm{C} 1$ '), $\mathrm{H}-5^{\prime}$ $\sim \mathrm{H}-1$ ', respectively, of the 2'-deoxyD-ribose sugar ring are all essentially available for reaction, i.e., hydrogen abstraction, with ${ }^{\circ} \mathrm{OH}$, a neutral, nondiscriminating and diffusible radical species, leading to DNA degradation. However, in duplex DNA, such as the plasmid DNA used in the DNA integrity assay, the preference for individual hydrogen atoms is seen to be in the order: $\mathrm{H}-5$ ' $>\mathrm{H}-4$ ' $>\mathrm{H}-2^{\prime} \approx \mathrm{H}-3^{\prime}>\mathrm{H}-1$ ', and this order of reactivity correlates well with the solvent accessibility of the individual hydrogen atoms in the sequence studied $[17,21,22]$. This is verified by one interesting result from the work of Close and coworkers, who irradiated single crystals of 2'-deoxy-guanosine-5'-monophosphate at low temperature and used ENDOR spectroscopy to detect radicals at all five carbon atoms [23]; radicals were not observed in irradiated duplex DNA [24]. Therefore, in the DNA integrity assay, the number of hydrogen atoms on each DNA sugar ring accessible to ${ }^{\circ} \mathrm{OH}$ is indeed very limited and ${ }^{\circ} \mathrm{OH}$ is instead presumably scavenged by the ingredients of the aqueous extracts of shallot powder examined in this study.

The results of the EPR experiments show that lyophilized shallot aqueous extract scavenges more ${ }^{\circ} \mathrm{OH}$ than its lyophilized garlic counterpart. The shallot extract demonstrates a stronger radical-scavenging ability against $\mathrm{ABT}^{\circ+}$ than that of garlic, as previously noted. In terms of radical scavenging ability, polyphenols, not diallyl sulfide, in allium vegetables are predominantly responsible for the initial reduction of the $\mathrm{ABT}^{\circ+}$ [13]. The total polyphenol content of dry bulbs of shallot and garlic are $674 \pm 37.0$ and $256 \pm 2.60 \mathrm{mg} / 100 \mathrm{~g}$ [25], respectively, which suggest that the difference in ${ }^{\circ} \mathrm{OH}$-scavenging ability between shallot and garlic aqueous extracts is most likely due to the difference in their polyphenol content.

The results obtained in the EPR experiments are similar to those in the DNA integrity assay, i.e., lyophilized shallot aqueous extracts exhibit scavenging activity against 'OH. In the DNA integrity assay, as described above, the lower solvent accessibility of the hydrogen atoms on the sugar moieties of the duplex DNA is believed to be the cause of ${ }^{\circ} \mathrm{OH}$ scavenging by shallot powder aqueous extracts. Similarly, the EPR experiments show that the 'OH-trapping efficiency of DMPO is only $35 \%$, due primarily to the competition between hydrogen abstraction of the 1-pyrroline ring and ${ }^{\circ} \mathrm{OH}$ addition to the $\mathrm{C}=\mathrm{N}$ of DMPO to generate EPR-active DMPO-OH [26]. This means that ${ }^{\circ} \mathrm{OH}$ is more likely to be scavenged by the polyphenols in the aqueous extracts of shallot and garlic powders. The low reactivity of DMPO toward ${ }^{\circ} \mathrm{OH}$ can also be explained by the fact that the nitrogen atom in the 1-pyrroline ring of DMPO is positively charged, making hydrogen atom abstraction and $\mathrm{C}=\mathrm{N}$ addition, both mediated by the electron-deficient ${ }^{\circ} \mathrm{OH}$, very difficult.

In summary, this study shows that shallot can be preserved in powder form for long-term storage, using three different protocols. Additionally, the results show that shallot powder aqueous extracts demonstrate either strong reducing power or ${ }^{\circ} \mathrm{OH}$-scavenging ability, depending on the assays conducted. Since shallot has been used as a food additive for centuries, the results presented here may increase the beneficial effects of shallot. 


\section{Acknowledgements}

The authors would like to thank the Department of Biotechnology at Ming Chuan University. They would also like to thank Ms. Yuo-Chi Chen of the Department of Chemistry at National Tsing Hua University (Hsinchu, Taiwan) for her kind assistance in EPR data collection. Finally, they are grateful to Mrs. Judy Wu and Dr. Michael McGarrgle, for proof-reading of the manuscript. This study was supported by the Undergraduate Student Research Fund of the Department of Biotechnology at Ming Chuan University.

\section{REFERENCES}

[1] S. V. Jovanovic, S. Steenken, M. Tosic and M. G. Simic, "Flavonoids as Antioxidants," Journal of the American Chemical Society, Vol. 116s, No. 11, 1994, pp. 48464851. doi:10.1021/ja00090a032

[2] C. A. Rice-Evans, N. J. Miller and G. Paganga, "Structure-Antioxidant Activity Relationships of Flavonoids and Phenolic Acids," Free Radical Biology and Medicine, Vol. 20s, No. 7, 1996, pp. 933-956. doi:10.1016/0891-5849(95)02227-9

[3] A. T. Diplock, J. L. Charleux, G. Crozier-Willi, F. J. Kok, C. Rice-Evans, M. Roberfroid, W. Stahl and J. VinaRibes, "Functional Food Science and Defence against Reactive Oxidative Species," British Journal of Nutrition, Vol. 80, No. 1, 1998, pp. S77-S112.

[4] F. Liu and T. B. Ng, "Antioxidative and free Radical Scavenging Activities of Selected Medicinal Herbs," Life Sciences, Vol. 66s, No. 8, 2000, pp. 725-735. doi:10.1016/S0024-3205(99)00643-8

[5] C. Huang, X. Zhang, Z. Qiao, L. Guan, S. Peng, J. Liu, R. Xie and L. Zheng, "A Case-Control Study of Dietary Factors in Patients with Lung Cancer," Biomedical and Environmental Sciences, Vol. 5s, No. 3, 1992, pp. 257-265.

[6] E. Fattorusso, M. Iorizzi, V. Lanzotti and O. Taglialatela-Scafati, "Chemical Composition of Shallot (Allium ascalonicum Hort.)," Journal of Agricultural and Food Chemistry, Vol. 50s, No. 20, 2002, pp. 5686-5690. doi:10.1021/jf020396t

[7] J. Kiviranta, K. Huovinen and R. Hiltunen, "Variation of Phenolic Substances in Onion," Acta pharmaceutica Fennica, Vol. 97s, No. 2, 1988, pp. 67-72.

[8] L. Terrance, G. Charles, F. Larry, K. H. William, C. Jose and N. Vicente, "Molecular Characterization of Quercetin and Quercetin Glycosides in Allium Vegetables. Their Effects on Malignant Cell Transformation," ACS Symposium Series, Vol. 50s, 1992, pp. 220-238.

[9] A. S. Salim, "Oxygen-Derived Free-Radical Scavengers Prolong Survival in Gastric Cancer," Chemotherapy, Vol. 38s, No. 2, 1992, pp. 135-144. doi:10.1159/000238953

[10] M. Tatsuta, H. Iishi, M. Baba, T. Mikuni, H. Narahara, N. Uedo and H. Yano, "Suppression by Iron Chelator Phenanthroline of Sodium Chloride-Enhanced Gastric Carcinogenesis Induced by N-methyl-N'-nitro-N-nitrosoguanidine in Wistar Rats," Cancer Letters, Vol. 191s, No. 1,
2003, pp. 9-16. doi:10.1016/S0304-3835(01)00797-2

[11] Y. Zhou, W. Zhuang, W. Hu, G. J. Liu, T. X. Wu and X. $\mathrm{T}$. $\mathrm{Wu}$, "Consumption of Large Amounts of Allium Vegetables Reduces Risk for Gastric Cancer in a MetaAnalysis," Gastroenterology, Vol. 141s, No. 1, 2011, pp. 80-89. doi:10.1053/j.gastro.2011.03.057

[12] J. Y. Kim and O. Kwon, "Garlic Intake and Cancer Risk: An Analysis Using the Food and Drug Administration's Evidence-Based Review System for the Scientific Evaluation of Health Claims," The American Journal of Clinical Nutrition, Vol. 89s, No. 1, 2009, pp. 257-264.

[13] N. Leelarungrayub, V. Rattanapanone, N. Chanarat and J. M. Gebicki, "Quantitative Evaluation of the Antioxidant Properties of Garlic and Shallot Preparations," Nutrition, Vol. 22s, No. 3, 2006, pp. 266-274. doi:10.1016/j.nut.2005.05.010

[14] A. Toure, X. Xu, T. Michel and M. Bangoura, "In Vitro Antioxidant and Radical Scavenging of Guinean Kinkeliba Leaf (Combretum micranthum G. Don) Extracts," Natural Product Research, Vol. 25s, No. 11, 2011, pp. 1025-1036. doi:10.1080/14786419.2010.482048

[15] G. K. Lopes, H. M. Schulman and M. Hermes-Lima, "Polyphenol Tannic Acid Inhibits Hydroxyl Radical Formation from Fenton Reaction by Complexing Ferrous ions," Biochimica et Biophysica Acta, Vol. 1472s, No. 1-2, 1999, pp. 142-152. doi:10.1016/S0304-4165(99)00117-8

[16] M. J. Burkitt and B. C. Gilbert, "Model Studies of the Iron-Catalysed Haber-Weiss Cycle and the AscorbateDriven Fenton Reaction," Free Radical Research Communications, Vol. 10s, No. 4-5, 1990, pp. 265-280. doi:10.3109/10715769009149895

[17] W. K. Pogozelski and T. D. Tullius, "Oxidative Strand Scission of Nucleic Acids: Routes Initiated by Hydrogen Abstraction from the Sugar Moiety," Chemical Reviews, Vol. 98s, No. 3, 1998, pp. 1089-1107. doi: $10.1021 / \mathrm{cr} 960437 \mathrm{i}$

[18] R. A. Floyd, "Hydroxyl Free-Radical Spin-Adduct in Rat Brain Synaptosomes. Observations on the Reduction of the Nitroxide," Biochimica et Biophysica Acta, Vol. 756s, No. 2, 1983, pp. 204-216.

doi:10.1016/0304-4165(83)90093-4

[19] B. Torok, J. Belagyi, B. Rietz and R. Jacob, "Effectiveness of Garlic on the Radical Activity in Radical Generating Systems," Arzneimittelforschung, Vol. 44s, No. 5, 1994, pp. 608-611.

[20] B. Yavuz, E. Bilensoy, I. Vural and M. Sumnu, "Alternative Oral Exemestane Formulation: Improved Dissolution and Permeation," International Journal of Pharmaceutics, Vol. 398s, No. 1-2, 2010, pp. 137-145. doi:10.1016/j.ijpharm.2010.07.046

[21] B. Balasubramanian, W. K. Pogozelski and T. D. Tullius, "DNA Strand Breaking by the Hydroxyl Radical Is Governed by the Accessible Surface Areas of the Hydrogen Atoms of the DNA Backbone," Proceedings of the $\mathrm{Na}$ tional Academy of Sciences of the United States of America, Vol. 95s, No. 17, 1998, pp. 9738-9743. doi:10.1073/pnas.95.17.9738

[22] M. A. Price and T. D. Tullius, "How the Structure of an 
Adenine Tract Depends on Sequence Context: A New Model for the Structure of $\mathrm{T}_{\mathrm{n}} \mathrm{A}_{\mathrm{n}}$ DNA Sequences," Biochemistry, Vol. 32s, No. 1, 1993, pp. 127-136. doi:10.1021/bi00052a018

[23] E. O. Hole, W. H. Nelson, E. Sagstuen and D. M. Close, "Free Radical Formation in X-Irradiated Anhydrous Crystals of Inosine Studied by EPR and ENDOR Spectroscopy," Radiation Research, Vol. 130s, No. 2, 1992, pp. 148-159. doi: $10.2307 / 3578271$

[24] D. M. Close, "Where Are the Sugar Radicals in Irradiated DNA?" Radiation Research, Vol. 147s, No. 6, 1997, pp.
663-673. doi: $10.2307 / 3579478$

[25] S. Tuntipopipat, C. Zeder, P. Siriprapa and S. Charoenkiatkul, "Inhibitory Effects of Spices and Herbs on Iron Availability," International Journal of Food Sciences and Nutrition, Vol. 60s, No. S1, 2009, pp. 43-55.

[26] A. J. Carmichael, K. Makino and P. Riesz, "Quantitative Aspects of ESR and Spin Trapping of Hydroxyl Radicals and Hydrogen Atoms in Gamma-Irradiated Aqueous Solutions," Radiation Research, Vol. 100s, No. 2, 1984, pp. 222-234. doi: $10.2307 / 3576343$ 